\title{
Evaluation on the Collection Efficiency and Performance of the Sound Pressure Machine Equipped with a HEPA Filter Eliminating Asbestos Particles
}

\author{
Wha Me Park ${ }^{1, a}$, Rew Jae Myung ${ }^{1}$, Key Young Kim ${ }^{1}$ \\ ${ }^{1}$ Institute of Environmental \& Industrial Medicine(IEIM), Han-yang University, Korea
}

\begin{abstract}
When the one-pass collection efficiency of each size of particles of the sound pressure machine equipped with a glass fiber HEPA filter to get rid of friable asbestos at the asbestos elimination field was evaluated, the collection efficiency of those with the size of $0.3 \mathrm{um}$ was examined to be $98.91 \%$. That of the particles of $0.5 \mathrm{um}$ size was proved to be $99.21 \%$ on average, which is a little bit higher than that of $0.3 \mathrm{um}$ size. The $1.0 \mathrm{um}$ particles showed $100 \%$ of efficiency, and the collection efficiency of each size had statistically meaningful differences.
\end{abstract}

\section{Introduction}

Asbestos is a mineral fiber found in nature. It is a fireresistant building material and comes in such different forms as asbestos tile and slate, etc. It is also widely used as a heat-resistant industrial good in household products, electric goods and jets. Use of anti-scattering products for high-risk asbestos work classified under the most stringent Class $\mathrm{H}$ in the UK in terms of carcinogenicity and hazard are advised in order to keep asbestos particles from scattering indoors $[1,2]$. Specifications for performance, test standards and evaluation of antiscattering products are still much too loose compared to those adopted outside of Korea, which limits the efforts to measure performance of the products. Most of them are not properly graded and sound pressure machines used for removing asbestos can rarely be applied indoors due to their high filter differential pressure, use of high electricity to deliver high air flow and high note [3]. Hence, an indicator that grades anti-scattering products based on their removal efficiency, performance evaluation and controls high-risk groups is needed.

\section{Research Methods}

\subsection{Specification and performance of high- performance air filter (HEPA filter)}

\subsubsection{Korea}

There is no certified specification or test standards for HEPA filters sold in the domestic market as of yet. HEPA filter manufacturers and marketers that have inhouse test lab may require all inspection before sales.
Others commission private test labs for an inspection if an outside certification is required. Two KS for domestic HEPA filter are KS A 4812: 2001 high-performance air filter for radioactive aerosol by Korean Agency for Technology and Standards (KATS) and KS B 6740: 1995 air filter performance test method for cleanroom by $\operatorname{KATS}[4,5]$.

KS A 4812: 2001 standard is radioactive aerosol with a view to remove nuclear facilities used by the powerful about to be in the fire flame is required, and air filter And allow efficiency, evaluation with a particle DOP (dioctyl phthalate) $0.15 \mu \mathrm{m}[6]$.

KS B 6740: 1995 standards are only distributed in the form of particles $0.3 \mu \mathrm{m}$ DOP standard is to the Particle Collection with a rate test [7].

\subsubsection{England}

British is embracing national standards to conform to the standard HEPA filter (EN 1822) of the European Union [8]. The European Union have specifications for the HEPA filter of a unified one. Matters concerning a total of five HEPA filters, divided by the specifications and type classification, test methods, measurement equipment, test methods is shown in each standard. The EN 1822 standard test aerosol dos, dop, paraffin oil, and aerosols, size is writing MPPS(Most Penetrating Particle Size). Sampling equipment is used to play Optical counter or Condensation nucleus counter.

National standard f HEPA filter of England 1) High efficiency air filters(EPA, HEPA and ULPA). C lassification, performance testing marking(BS EN 18221: 2009), 2) High efficiency air filters(EPA, HEPA and ULPA). Aerosol production, measuring equipment, particle counting statistics(BS EN 1822-2: 2009), 3) High

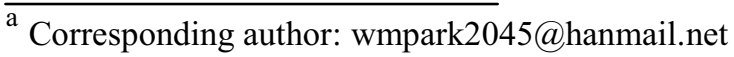


efficiency air filters(EPA, HEPA and ULPA). Testing flat sheet filter media(BS EN 1822-4: 2009) 4) High efficiency air filters(EPA, HEPA and ULPA). Determining leakage of filter elements(scan method)(BS EN 1822-4: 2009) 5) High efficiency air filters(EPA, HEPA and ULPA). Determining the efficiency of filter elements (scan method)(BS EN 1822-5: 2009)

\subsubsection{United States}

There are many HEPA filter standards for using the United States. Each rule all developed for different history of the methods are used has been flouting respectively. The specification used in KS standards, testing institutions and many standards a descendant of HEPA filter of the United States.

In 1956, how dop MIL-STD-282<Filter Unit, Protective Clothing, Gas-mask Components and Related Products $>$ to use was published, Heat the liquid into this standard the test aerosol DOP, superimposes steam and concentrate again make the particles an average of 0.3 $\mu \mathrm{m}$.

Published the ANSI/UL 586 <Air Filter Units> in 1959.

In 1975 and 1976 ANSI N 45.8 Committee < American Society of Mechanical Engineers Committee on Nuclear Air and Gas Treatment> ASME/ANSI N510 and ASME N509published. ASME/ANSI N510-2007 is the latest edition.

Between 1992 and 1993 Institute of Environmental Sciences and Technology the HEAP/ULPA filter test standards-IEST-RP-CC007.1: 1992 <Testing ULPA Filters $>$, IEST-RP-CC001.3:1993 <HEAP and ULPA Filters $>$ IEST-RP-CC006.2:1993 <Testing Cleanrooms $>$ - publication series against the brothers.

In 2005 published the IEST-RP_CC001.4 $<$ HEPA and ULPA Filters $>$, IEST-RP-CC04. $2<$ HEAP and ULPA Filter Tests>.

\subsection{Specification and performance of sound pressure machines}

\subsubsection{Korea}

Specification of sound pressure machines is based on approval certification that requires(KOSHA Guide H-532009) [9-11] 1) HEPA filter installation (higher than $99.97 \%$ in DOP removal efficiency), 2) installation of pre-treatment filter in HEPA filter front, 3) installation of filter differential pressure gauge, 4) successful leak test, 5) installation of air blower in filter rear and 6) installation of equipment preventing scattering during mobility. Sound pressure machines should be loaded with HEPA filter $(99.97 \%$ in removal efficiency) and pass leak test (99.95\% in removal efficiency) based on approval certification standards. (Table 1), [12]

Sound pressure of an sale in the country to a survey of performance requirements is shown below. Sound pressure flow rate, which is the most important when using a machine sound pressure If I had not displayed in a $42 \%$ at its maximum. Sound pressure often not given leak testing is a $42 \%$ and sound pressure on a bi ban song for the inside flap if they are not installed, and a $58 \%$. Flow controller $29 \%$ if they are not installed. (Table 2)

Table 1. Producing sound pressure machine in domestic capacity.

\begin{tabular}{|c|c|}
\hline Rate $\left(\mathbf{m}^{\mathbf{s}} / \mathbf{h}\right)$ & Number \\
\hline $500 \sim 1,000$ & 3 \\
\hline $1,000 \sim 2,000$ & 4 \\
\hline $2,000 \sim 3,000$ & 4 \\
\hline 3,000 & 1 \\
\hline
\end{tabular}

Table 2. Domestic performance installation requirements for producing sound pressure machi.

\begin{tabular}{|l|c|c|}
\hline & Yes & No \\
\hline $\begin{array}{l}\text { Sound pressure flap } \\
\text { bibansong installation } \\
\text { inside the machine }\end{array}$ & 3 & 4 \\
\hline $\begin{array}{l}\text { Intromitter gasket(sea } \\
\text { wave filters and } \\
\text { between cases) }\end{array}$ & 7 & 0 \\
\hline $\begin{array}{l}\text { Flow bean or damper } \\
\text { setup }\end{array}$ & 5 & 2 \\
\hline $\begin{array}{l}\text { Sound pressure meter } \\
\text { upward pressure on an } \\
\text { installation }\end{array}$ & 6 & 1 (Nonresponse) \\
\hline $\begin{array}{l}\text { Alarm installations for } \\
\text { the sound pressure } \\
\text { machine }\end{array}$ & 5 & 2 \\
\hline $\begin{array}{l}\text { See flow in the external } \\
\text { sound pressure machine }\end{array}$ & 4 & 3 \\
\hline $\begin{array}{l}\text { See jejonyeon in the } \\
\text { sound pressure machine }\end{array}$ & 7 & 0 \\
\hline $\begin{array}{l}\text { Sound pressure machine } \\
\text { displayed } \\
\text { manufacturer name or } \\
\text { mark }\end{array}$ & 7 & 0 \\
\hline $\begin{array}{l}\text { Test whether the sound } \\
\text { pressure machine }\end{array}$ & 4 & 3 \\
\hline
\end{tabular}

\subsubsection{England}

Performance of Sound Pressure in England for national standards-BS 8520-2: 2009 Equipment used in the controlled removal of asbestos-containing materials- Part 2: Negative pressure units-Specification [13-15 ].

The purpose of this standard HEPA filter to be used, remove asbestos containing materials equipped with portable sound pressure to specify the performance.

Be easy to clean the outer case, apartment area that is signed three times made of plastic welding, head end when moved to the flaps, prevent reflux filter cover, may be able to protect the front wheels and handles, HEPA filter, air inlet Ministry of the wheel, A manometer on the sound-pressure machine specifications show when I was stuck in traffic filters HEPA should be included.

The leakage test specifications Household and similar electrical appliance. Safety. Particular requirements for wet and dry vacuum cleaners including power brush for commercial use (BE EN 60335-2.69: 2009) in Annex a 
Carrying yellow dusts shows. According to this standard, should more than $99.7 \%$ efficiency HEPA filter and mounted on the sound pressure machine, Maximum leakage should be allowed only $0.005 \%$ from the leakage tests. Leakage test the same grades $\mathrm{H}$ a vacuum cleaner as applicable.

\subsubsection{United States}

a) OSHA class I of working with asbestos rigid an entire engineering standard [11].

OSHA law, used asbestos services in the dismantling and removal work, sound pressure specified for information regarding the structure of a particular point about not be, and sound pressure, using a specified.

- enclosure internal sound pressure measurements, $5 \mathrm{~Pa}(0.5 \mathrm{~mm} \mathrm{H} 2 \mathrm{O})$ to do maintenance.

- of differential pressure measurement.

- flow of air, ease, from worker to perform.

- Install a smoke test to detect the flow and air leakage.

b) American National Standards Institute and American Industrial Hygiene Association and portable ventilation system specifications.

American National Standards Institute and the American Industrial Hygiene Association to jointly published by mobile portable some matters were about standards in ventilation systems in the specification of Ventilation SystemInclude.

\subsection{Evaluation of commercial sound pressure machines' one-pass dust collection efficiency}

Sound pressure machines commonly used to remove asbestos were used for the evaluation and dust collection efficiency of glass fiber HEPA mounted in sound pressure machines was evaluated. (Figure 1)

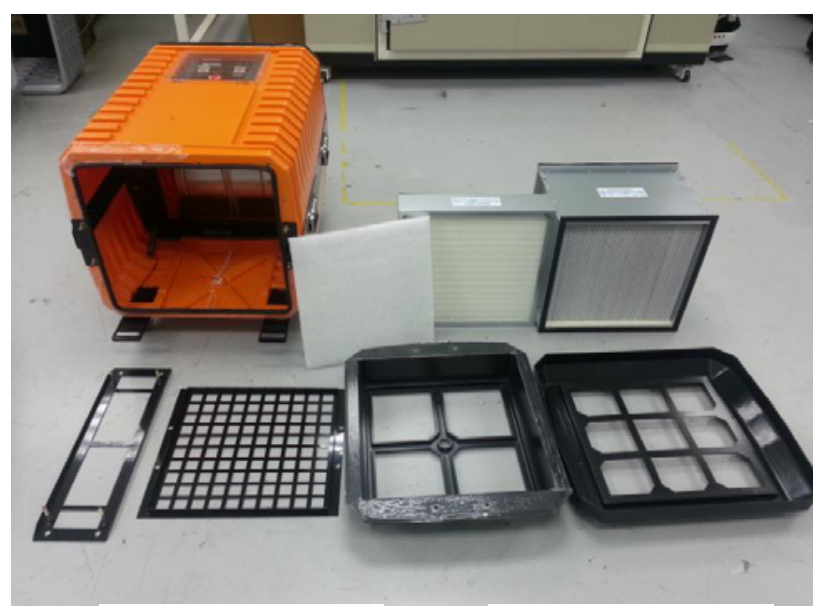

Figure 1. Commercial sound pressure machine for removing asbestos.

Affiliations of authors should be typed in italic 8point Arial. They should be preceded by a numerical superscript corresponding to the same superscript after the name of the author concerned. Please ensure that affiliations are as full and complete as possible and include the country. (Figure 2)

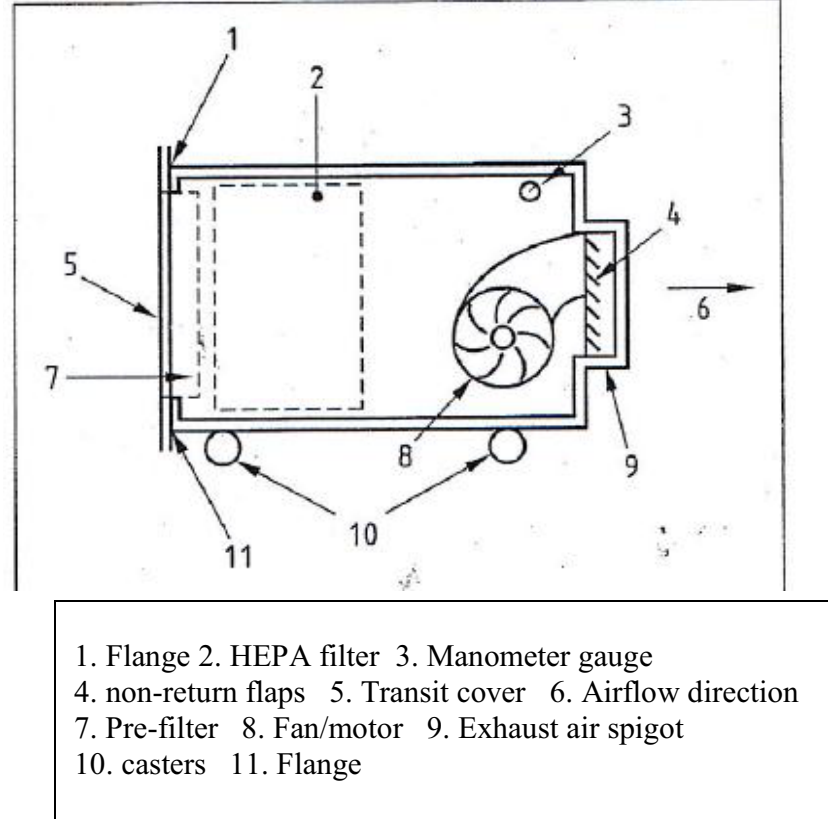

Figure 2. Sound pressure machine configuration.

\subsection{Measurement of one-pass dust collection efficiency}

Airborne Particle Counter (Rion, KC-01C) was used to evaluate dust collection efficiency of all sound pressure machines. Airborne Particle Counter applied light scattering method to measure particle density and measured particles $0.3 \mu \mathrm{m}, 0.5 \mu \mathrm{m}$ and $1 \mu \mathrm{m}$ in diameter. Flow Meter sampled $0.5 \mathrm{~L} / \mathrm{min}$ of flux and sample volume was $1 \mathrm{~L}$ or $2.83 \mathrm{~L}$. Particle density from sound pressure machine's inlet and outlet was alternately measured after air volume stabilized. (Figure 3 )

$$
\eta=\left(1-C_{0} / C_{i}\right) X 100
$$

$\eta$ : Dust collection efficiency $(\%)$

$C_{0}$ : Particle density of outlet $(\mathrm{ea} / \mathrm{L})$

$C_{i}$ : Particle density of air inlet $(\mathrm{ea} / \mathrm{L})$

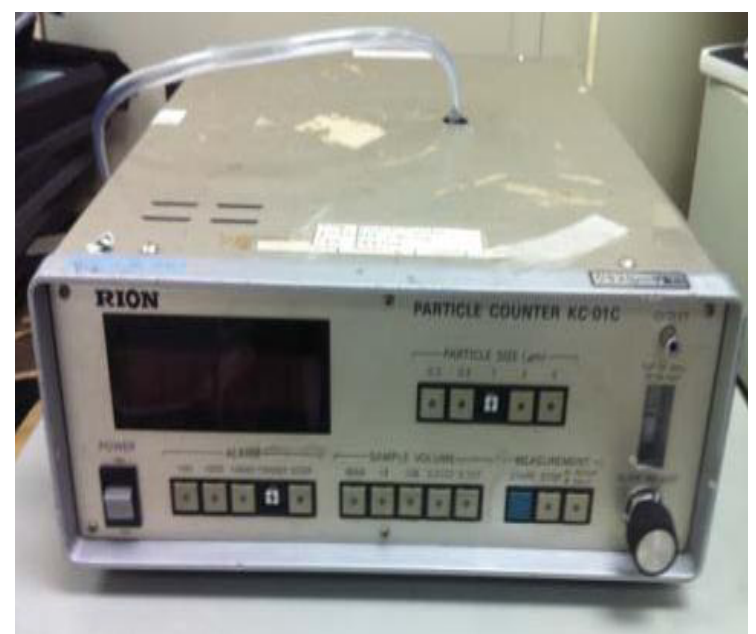

Figure 3. Airborne Particle Counter.

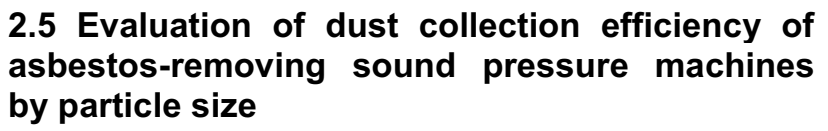

2.5 Evaluation of dust collection efficiency of by particle size 
The following table presents evaluation of one-pass dust collection efficiency of a sound pressure machine mounted with glass fiber HEPA filter. Efficiency is evaluated by particle size in a commercially-used sound pressure machine. (Table 3)

Table 3. Dust collection efficiency of asbestos-removing sound pressure machine mounted with glass fiber HEPA filter by particle size.

\begin{tabular}{|c|c|c|c|c|c|c|c|}
\hline \multirow{2}{*}{$\begin{array}{c}\text { Filter } \\
\text { Type }\end{array}$} & $\begin{array}{c}\text { Particle } \\
\text { Size } \\
(\boldsymbol{\mu m})\end{array}$ & $\mathbf{N}$ & \multicolumn{5}{|c|}{ Removal Efficiency (\%) } \\
\cline { 4 - 7 } & & Mean & $\begin{array}{c}\text { Std. } \\
\text { Dev }\end{array}$ & Min & Max & $\begin{array}{c}\text { P- } \\
\text { value }\end{array}$ \\
\hline \multirow{2}{*}{$\begin{array}{l}\text { Fiber } \\
\text { Glass }\end{array}$} & 0.30 & 10 & 98.91 & 0.110 & 98.72 & 99.07 & \\
\cline { 2 - 7 } & 0.50 & 10 & 99.21 & 0.735 & 97.71 & 100 & $<0.05$ \\
\cline { 2 - 6 } & 1.0 & 10 & 100 & 0 & 100 & 100 & \\
\hline
\end{tabular}

\section{Study Results}

Evaluation of a one-pass dust collection efficiency of a commercial sound pressure machine mounted with glass fiber HEPA filter by particle size indicates dust collection efficiency of $0.3 \mathrm{um}$ in particle size to average at $98.91 \%$. That of 0.5 um and 1.0 um in particle size showed a dust collection efficiency of $99.21 \%$ on average and $100 \%$.

The dust collection efficiency test is based on KS B 6740 using mono-dispersed 0.3 um DOP particle. Performance evaluation requires particles $0.3 \mathrm{um}$ in size to show a dust collection efficiency exceeding $99.97 \%$. Dust collection efficiency for each size in the test shows a statistically significant difference.

\section{Acknowledgements}

This study was funded by the Korea Ministry of Environment(MOE) as "the Environmental Health Action Program" [11].

\section{References}

1. Tsai, P.P., Gibson, H.S., and Gibson, P., Different electrostatic methods for making electret filters. Journal of Electrostatics, 54, 333-341(2002)

2. Young Man Roh, Mi Hee Seok, Kang Yoon Kim, Tae Jae Cho, Sang Hyo Sim, Hyun Cheol Ha., Study on "Infrastructure Standards to Remove Asbestos",
Occupational Safety \& Health Research Institute(2008)

3. Tae Hyung Kim, Hyun Cheol Ha, Kang Yoon Kim, Jong Cheol Kim, Yoo Jin Jung., "Study on Asbestos Removal Guidelines in Buildings to Prevent Scattering, Ministry of Environmen"t(2010)

4. Health and Safety Executive. Approved Code of Practice and guidance, Work with materials containing asbestos, Control of Asbestos Regulations. (2006)

5. Korea Air Cleaning Association. High-performance air filter test method(2009)

6. Korean Agency for Technology and Standards. High-performance air filter for radioactive aerosol, KS A 4812(2001)

7. Korean Agency for Technology and Standards. Air filter performance test method for clean room, KS B 6740(1995)

8. British Standards Institution. High efficiency air filters, Aerosol production, measuring equipment, particle counting statistics, BS EN 1822-2 (2009)

9. Health and Safety Executive. Approved Code of Practice and guidance, The management of asbestos in non-domestic premises(2006)

10. Health and Safety Laboratory. Investigation into the effectiveness of modular hygience unit(2001)

11. Occupational Safety and Health Administration, "Safety and Health Regulations for Construction" (1926.1101). Retrieved on(2012-01-10)

12. Korea Occupational Safety and Health Agency. Recommended guidelines for demolition and removal procedures when working with asbestos, KOSHA Guide H-70-2012(2012)

13. British Standards Institution. Controlled wetting of asbestos-containing materials-Specification, Equipment used in the controlled removal of asbestos-containing materials-Part 1, BS 8520-1 (2009)

14. British Standards Institution. Negative pressure unitSpecification, Equipment used in the controlled removal of asbestos-containing materials-Part 2, BS 8520-2(2009)

15. British Standards Institution. Operation, Cleaning and maintenance of Class $\mathrm{H}$ vacuum cleaners-Code of practice, Equipment used in the controlled removal of asbestos-containing materials-Part 3, BS 8520-3(2009) 